\title{
Asn-Gly-Arg-modified polydopamine-coated nanoparticles for dual-targeting therapy of brain glioma in rats
}

\author{
Jiangang $\mathrm{Hu}^{1,2}$, Xiang Zhang ${ }^{1,2}$, Zuhuang Wen ${ }^{3}$, Ying Tan ${ }^{1}$, Ning Huang ${ }^{1}$, Si Cheng ${ }^{4}$, \\ Huzhi Zheng ${ }^{3}$, Yuan Cheng ${ }^{1}$ \\ ${ }^{1}$ Department of Neurosurgery, the Second Affiliated Hospital of Chongqing Medical University, Chongqing, 400010, China \\ ${ }^{2}$ Chongqing Key Laboratory of Ultrasound Molecular Imaging, Institute of Ultrasound Imaging of Chongqing Medical \\ University, Chongqing, 400016, China \\ ${ }^{3}$ College of Chemistry and Chemical Engineering, Southwest University, Chongqing, 400715, China \\ ${ }^{4}$ Department of Orthopaedics, the First Affiliated Hospital of Chongqing Medical University, Chongqing, 400016, China \\ Correspondence to: Huzhi Zheng, email: zhenghz@swu.edu.cn \\ Yuan Cheng, email: chengyuan023@aliyun.com \\ Keywords: Asn-Gly-Arg, polydopamine, dual-targeting, gliomas
}

Received: May 29, $2016 \quad$ Accepted: August 26, $2016 \quad$ Published: September 15, 2016

\section{ABSTRACT}

The blood-brain barrier (BBB) is the major clinical obstacle in the chemotherapeutic management of brain glioma. Here we synthesized a pH-sensitive dual-targeting doxorubicin (DOX) carrier to compromise tumor endothelial cells, enhance BBB transportation, and improve drug accumulation in glioma cells. The drug delivery system was constructed with polydopamine (PDA)-coated mesoporous silica nanoparticles (NPs, MSNs) and the PDA coating was functionalized with Asn-Gly-Arg (NGR), a ligand with specific affinity for cluster of differentiation 13 (CD13). MSNDOX-PDA-NGR showed a higher intracellular accumulation in primary brain capillary endothelial cells (BCECs) and $C 6$ cells and greater BBB permeability than the nontargeting NPs (MSN-DOX-PDA) did in vitro. EX vivo and in vivo tests showed that MSN-DOX-PDA-NGR had a higher accumulation in intracranial tumorous tissue than the undecorated NPs did. Furthermore, the antiangiogenesis and antitumor efficacy of MSN-DOX-PDA-NGR were stronger than that of MSN-DOX-PDA. Therefore, these results indicate that the dual-targeting vehicles are potentially useful in brain glioma therapy.

\section{INTRODUCTION}

The delivery of chemotherapeutic agents for the treatment of central nervous system diseases such as brain glioma is still a major challenge because most chemotherapy drugs cannot penetrate the blood brain barrier (BBB) to reach the brain tumor cells $[1,2]$. Numerous attempts have been made to overcome this barrier, but trans-BBB drug delivery is still a challenge. Recently, an efficient receptor-mediated, stimuliresponsive controlled drug release system for penetrating the BBB and targeting brain tumor cells has attracted considerable attention [3-6].

As a marker for angiogenic vasculature, the aminopeptidase $\mathrm{N}$ (cluster of differentiation 13, CD13) is overexpressed in cancerous tissues including neovascular endothelial cells and various tumor cells and has been widely studied in tumor angiogenesis and invasion [7]. A peptide containing the Asn-Gly-Arg (NGR) motif, which binds CD13 has also been associated with chemotherapeutic drug delivery [8-10]. However, targeting and compromising glioma cells remain challenging even with these delivery systems. Therefore, we designed an inorganic-organic hybrid nanoparticle (NP)-based dualtargeting carrier (tumor vascular- and tumor-targeting), incorporating the advantages of mesoporous silica NPs (MSN) and polydopamine (PDA).

MSN are ideal nanocarriers for chemotherapy drugs because of their low density, large surface area, high pore volume, high drug-loading capacity, and excellent biocompatibility [11-14]. A key step in constructing the controlled drug release carrier was the generation of "gatekeepers" on the MSN surface to seal the drug molecules inside the mesoporous core and control the drug 
Table 1: Size and zeta potential of nanoparticles (NPs, $n=3)$

\begin{tabular}{lccc}
\hline & \multicolumn{2}{c}{ Size $(\mathbf{n m})$} & \multirow{2}{*}{ Zeta potential (mv) } \\
\cline { 2 - 4 } & TEM & DLS & \\
\hline MSN-DOX-PDA & $152.3 \pm 0.97$ & $156.1 \pm 1.25$ & $-24 \pm 0.96$ \\
MSN-DOX-PDA-NGR & $160.1 \pm 1.49$ & $168.0 \pm 1.32$ & $-22 \pm 0.97$ \\
\hline
\end{tabular}

release from MSN in response to the $\mathrm{pH}$-stimulus [15]. PDA, a mussel adhesive protein mimetic, has the potential to act as the $\mathrm{pH}$-sensitive gatekeeper and conjugate the NGR to enhance targeting, owing to the versatility in modifying [16], easiness in surface functionalization with NGR motif via Michael addition reactions [17, 18], negligible cytotoxicity in drug delivery $[19,20]$.

Therefore, for the first time, we synthesized a controlled release and dual-targeting system using PDAcoated MSN as the doxorubicin (DOX) carrier and conjugating NGR as the targeting ligand (MSN-DOXPDA-NGR) to dual-target the endothelial and glioma cells. Primary rat brain capillary endothelial cells (BCECs) and C6 cells were chosen as the model of tumor endothelial and tumor cells, respectively. The drug delivery system was characterized using transmission electron microscopy (TEM) and dynamic light scattering (DLS). The drug release behavior, cell cytotoxicity, uptake assays, and dual-targeting effects were evaluated in vitro while the antiangiogenesis and antitumor effects were investigated in vivo.

\section{RESULTS}

\section{Characterization of dual-targeted NPs}

NPs with the size of 100-200 nm are believed to have the most potential for persistent circulation and exhibit the best enhanced permeation and retention (EPR) effect [21]. Therefore, we selected MSN with a mean particle diameter of $150 \mathrm{~nm}$ to prepare the MSNDOX-PDA-NGR. DOX was first loaded into the silica mesopores and then coated with PDA via oxidative selfpolymerization of dopamine. The surface of the MSNDOX-PDA NPs was then modified with NGR via a Michael addition. The TEM images showed that the NPs were spherical and had a smooth surface with a size of approximately $160 \mathrm{~nm}$. The dehydration and shrinkage of the NPs during the preparation for TEM observation may lead to the smaller diameter compared with the results from DLS (Table 1 and Figure 1A). The NGR modification slightly increased the particle size and zeta potential (Table 1 and Figure 1B). It has been indicated that the negatively-charged surface of the drug carrier system has higher blood compatibility and better targeting effect in vivo than the positively-charged carrier surface does $[22,23]$. The loading of DOX and the modification of the PDA coating were also reflected in the color change of the solution. The white-colored MSN solution turned brick red after DOX loading and subsequently turned dark brown after the modification of the PDA coating (Figure 1C). The loading content (LC), encapsulation efficiency (EE), and NGR conjugation efficiency (CE) values were $19.02 \%, 40.84 \%$, and $41.6 \%$, respectively, under the present experimental conditions.

Because most tumorous tissues have low extracellular $\mathrm{pH}$ values, especially inside the endosomal $(\mathrm{pH}, 5.5-6.0)$ and lysosomal $(\mathrm{pH}, 4.5-5.0)$ compartments $[24,25]$, we conducted the DOX release profiles at $\mathrm{pH}$ 4.5 and 7.4. As shown in Figure 1D, only a very small amount of DOX was released in the neutral PBS (pH 7.4). However, the release rate dramatically improved and the cumulative release rate of DOX was approximately $50 \%$ within $24 \mathrm{~h}$ at $\mathrm{pH} 4.5$. The $\mathrm{pH}$-sensitivity of the carriers suggested that the NPs were almost stable in plasma conditions but allowed sustained drug release in tumorous conditions, which facilitated drug accumulation in the tumorous vasculature and intercellular distribution in tumor cells.

\section{Receptor expression level in targeted cells}

CD13 is expressed exclusively on the angiogenic endothelial and not normal vasculature [26]. In addition, the high level of vascular endothelial growth factor (VEGF) released by $\mathrm{C} 6$ cells strikingly could upregulate the $\mathrm{CD} 13$ level in primary cells during angiogenesis [27, 28]. Therefore, we established a $\mathrm{C} 6$ and primary brain capillary endothelial cells (BCEC) cocultured model to investigate whether the $\mathrm{CD} 13$ level in BCEC cells was upregulated. The flow cytometry and western blotting showed a dramatic elevation of the CD13 level in BCECs cocultured with $\mathrm{C} 6$ cells (BCEC-C6). In addition, the level was relatively higher in $\mathrm{C} 6$ cells than it was in the primary astrocytes (AC), BCEC, and BCECs cocultured with $\mathrm{AC}$ cells (BCEC-AC) (Figure $2 \mathrm{~A}$ and $2 \mathrm{~B}$ ). The results indicate that $\mathrm{C} 6$ cells successfully induced the BCECs and the tumorous vasculature endothelial cell model was established.

\section{Cellular uptake of dual-targeted NPs}

To determine the specific recognition and uptake capacity of MSN-DOX-PDA-NGR towards target cells, we performed laser scanning confocal microscopy and flow cytometry on $\mathrm{C} 6$ and BCEC-C6 cells after 

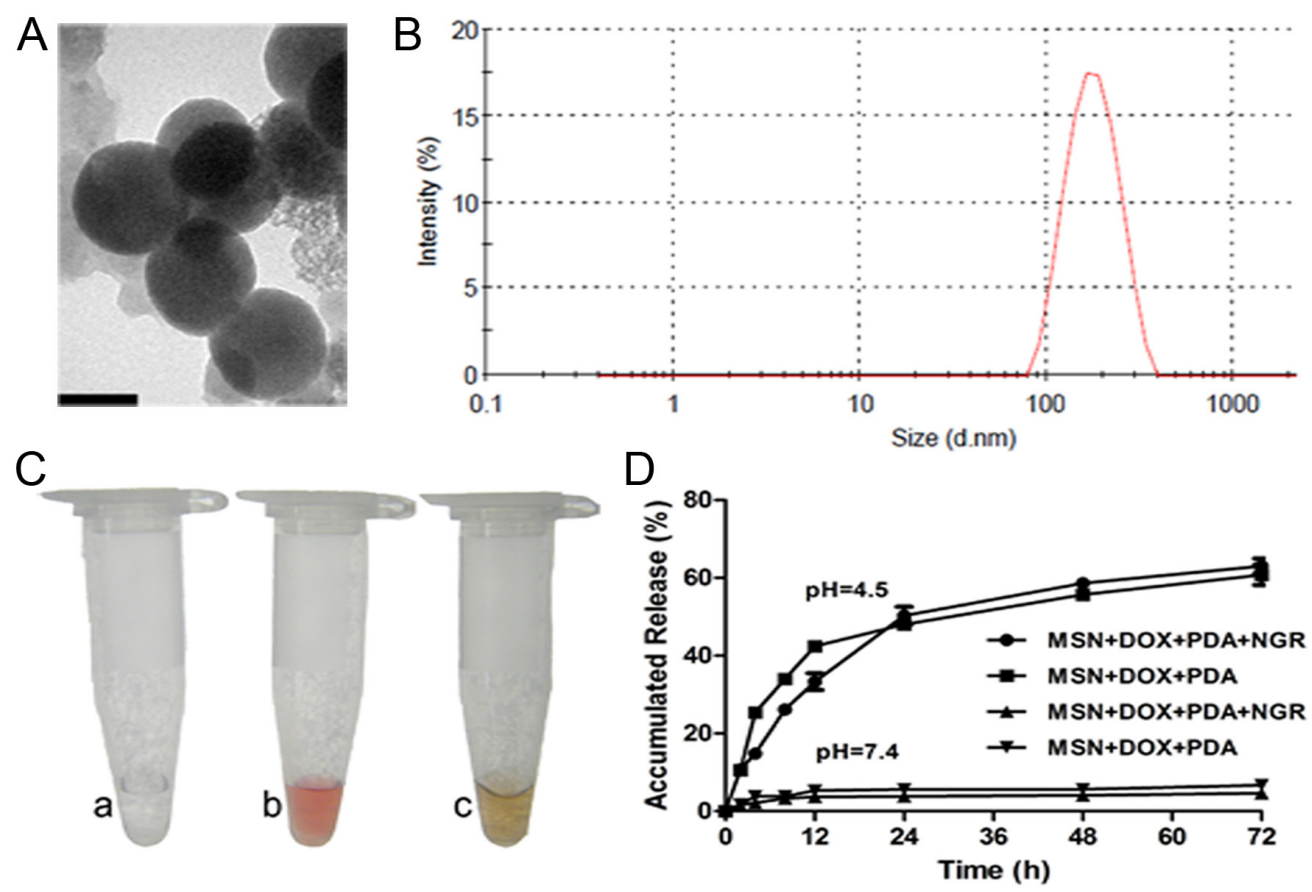

Figure 1: Characterization of dual-targeted NPs. A. Transmission electron microscopy (TEM) images of MSN-DOX-PDA-NGR NPs. B. Particle size distribution of MSN-DOX-PDA-NGR NPs. C. Color change of NPs solution. D. In vitro release profiles of DOX from different drug carriers in different PBS samples at $\mathrm{pH}$ (4.5) and $\mathrm{pH}$ (7.4). Scale bar, $100 \mathrm{~nm}$.
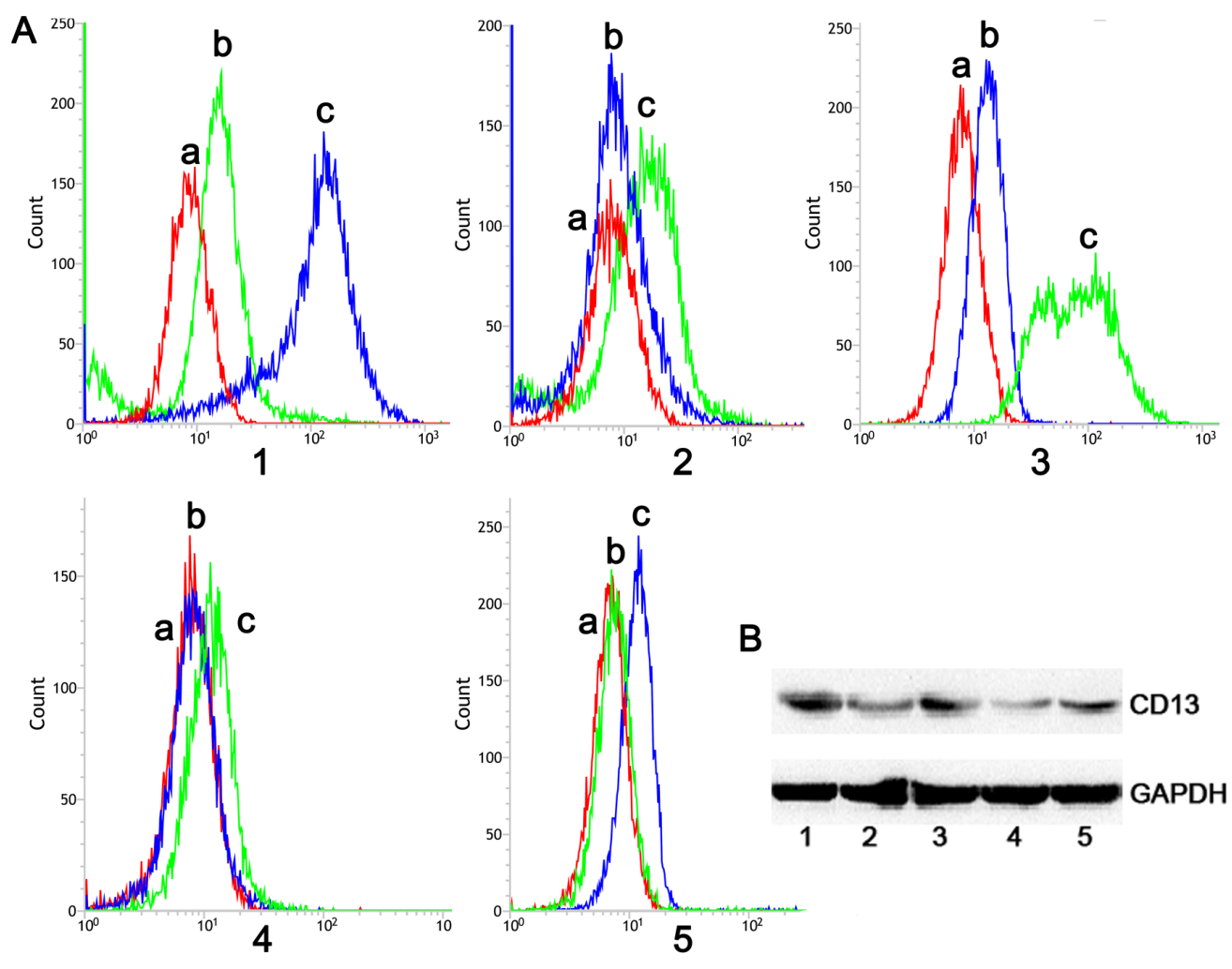

Figure 2: Flow cytometry and western blot analysis of NP-treated cells. A. Flow cytometry and B. western blotting analysis of CD13 protein expressed in (1) BCEC-C6, (2) BCEC, (3) C6, (4) astrocytes, and (5) BCEC-AC cells; (a) negative control, (b) mouse IgG2a $\mathrm{K}$ Isotype control, and (c) anti-rat CD13 antibody (FITC). 
treatment with different DOX formulations. Both C6 and BCEC-C6 cells in the MSN-DOX-PDA-NGR group showed an obviously higher fluorescence intensity than those in MSN-DOX-PDA group did (Figure 3A and 3B). The identical results was also found by flow cytometry, the fluorescence intensity of the MSN-DOX-PDA-NGR group increased significantly compared with that of the undecorated NPs group ( $\sim 3.27$ - and 5.50-fold for BCEC-C6 and C6, respectively). However, the adding of free NGR significantly inhibited the uptake of MSNDOX-PDA-NGR (Figure 3C-3E). The NGR-mediated specific binding between MSN-DOX-PDA-NGR and glioma cells was also found in U251 cells but not in GL261 (Supplementary Figure S1). Furthermore, flow cytometry confirmed that, relatively to GL261, C6 and U251 have a more powerful binding affinity to anti-CD13 antibody (FITC) in our preliminary experiments (data not shown). Taken together, MSNDOX-PDA-NGR specifically recognize and abundantly bind to BCEC-C6 and C6 cells through the high level of CD13.
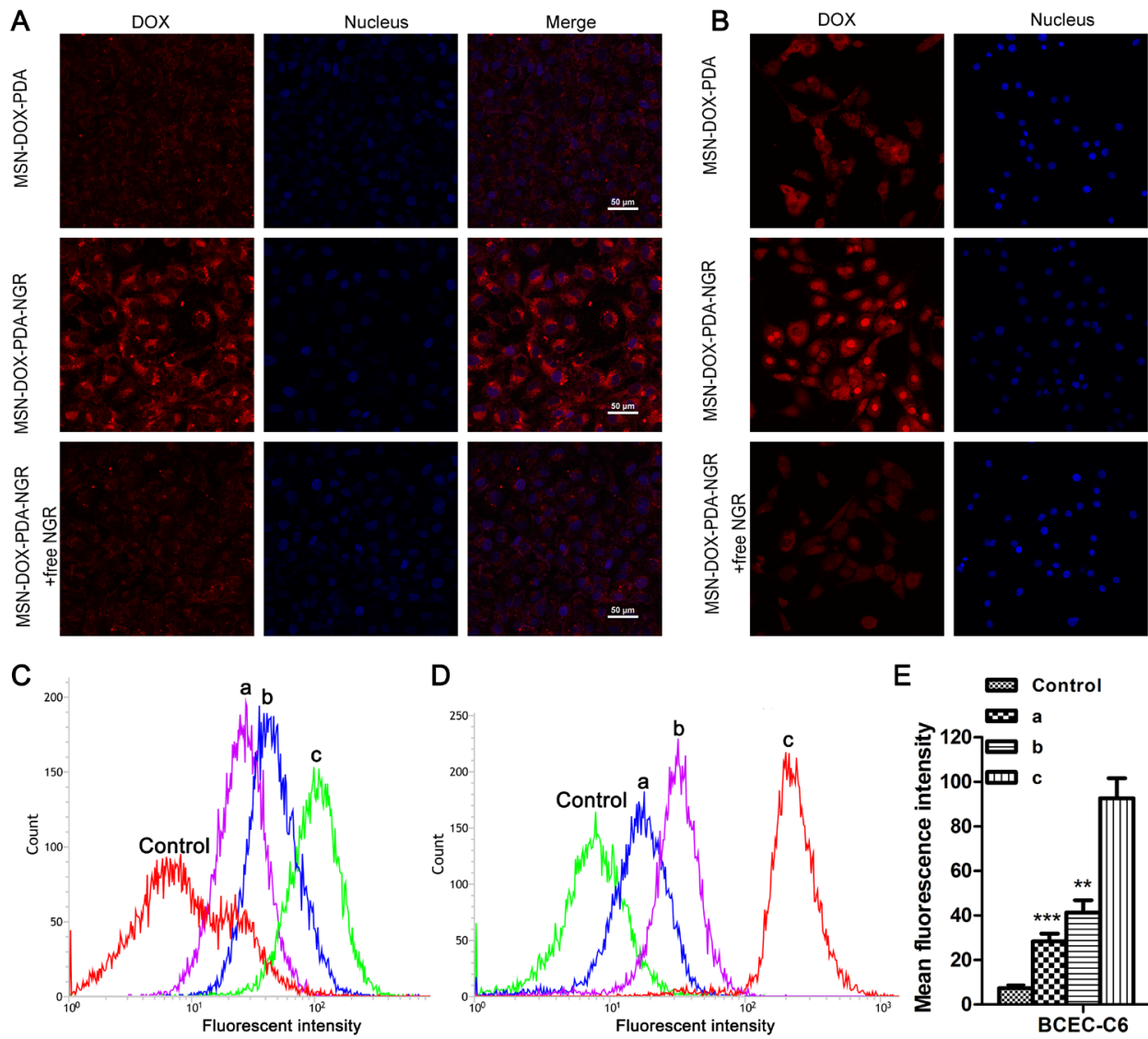

E

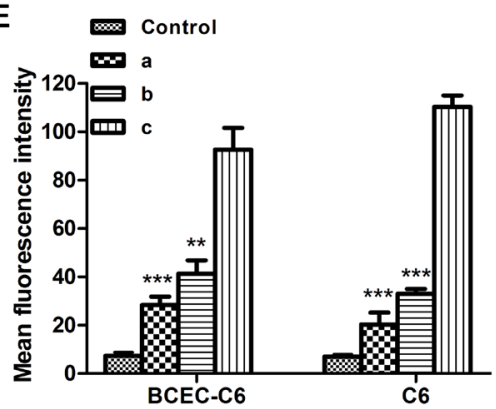

Figure 3: Qualitative and quantitative analysis of drug-loaded NPs in BCEC-C6 and C6 cells. Confocal images of A. BCEC-C6 and B. C6 cells after treatment with different DOX formulations for 4 h. Flow cytometric analysis of C. BCEC-C6 and D. C6 cells after treatment with different DOX formulations for $2 \mathrm{~h}$. E. Quantitative analysis of mean fluorescence intensity in different DOX formulation group. Cell nuclei were stained using DAPI (blue) and DOX (red). (a) MSN-DOX-PDA, (b) MSN-DOX-PDA-NGR + free NGR, and (c) MSN-DOX-PDA-NGR. ${ }^{* *} p<0.01$ and ${ }^{* * *} p<0.001$ compared with $\mathrm{c}(\mathrm{n}=3)$. 
cytotoxicity observed in C6 cells, MSN-DOX-PDA-NGR did not exhibit an improved antitumor effect on GL261 cells compared with MSN-DOX-PDA and MSN-DOXPDA-NGR + free NGR. This MSN-DOX-PDA-NGR resistance was evidenced by their no difference of $\mathrm{IC}_{50}$ values $(p>0.05)$ (Supplementary Figure S2C and S2D). The blank NPs were biocompatible since the cell viability was $>80 \%$ at a concentration of $1000 \mu \mathrm{g} / \mathrm{mL}$ of MSNPDA-NGR and a 96-h treatment period (Figure 4B). In summary, owing to high CD13 level and subsequently MSN-DOX-PDA-NGR sensitization, C6 was selected as tumor cell model for the further studies.

\section{Cellular uptake mechanism of dual-targeted NPs}

To elucidate the endocytosis pathways of the MSN-DOX-PDA-NGR that were activated after their
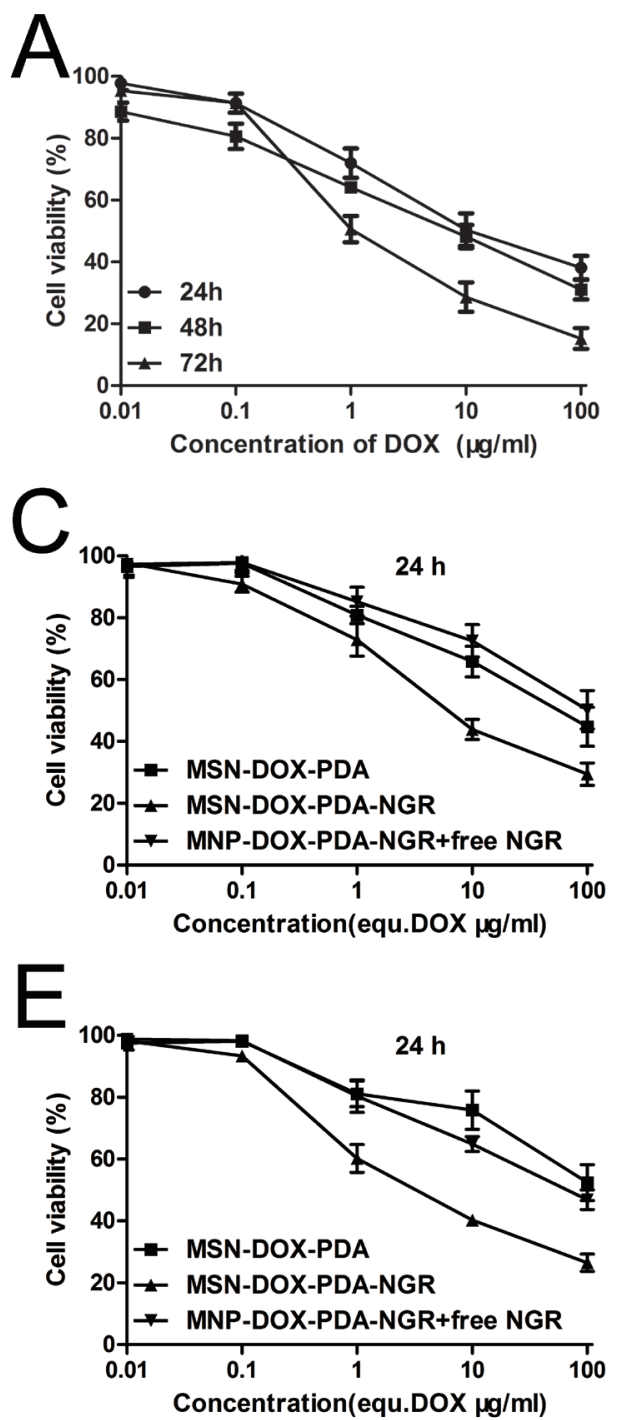

recognition by the CD13 expressed on glioma cells and endothelial cells, the effects of different endocytosis inhibitors were evaluated in $\mathrm{C} 6$ and BCEC-C6 cells. As shown in Figure 5, the uptake of MSN-DOX-PDA-NGR by C6 cells was significantly inhibited by NaN3 (energy depletion agent), Cyto-B (macropinocytosis inhibitor), CPZ (clathrin-mediated endocytosis inhibitor), and monensin (lysosome inhibitor), but not by filipin, genistein (caveolae-mediated endocytosis inhibitor) or BFA (Golgi apparatus and intracellular trafficking inhibitor). Furthermore, only genistein did not inhibit the uptake of MSN-DOX-PDA-NGR by the BCEC-C6 cells. These results indicate that the MSN-DOX-PDANGR uptake was energy-dependent and stimulated by clathrin-mediated endocytosis and the macropinocytosis pathway.
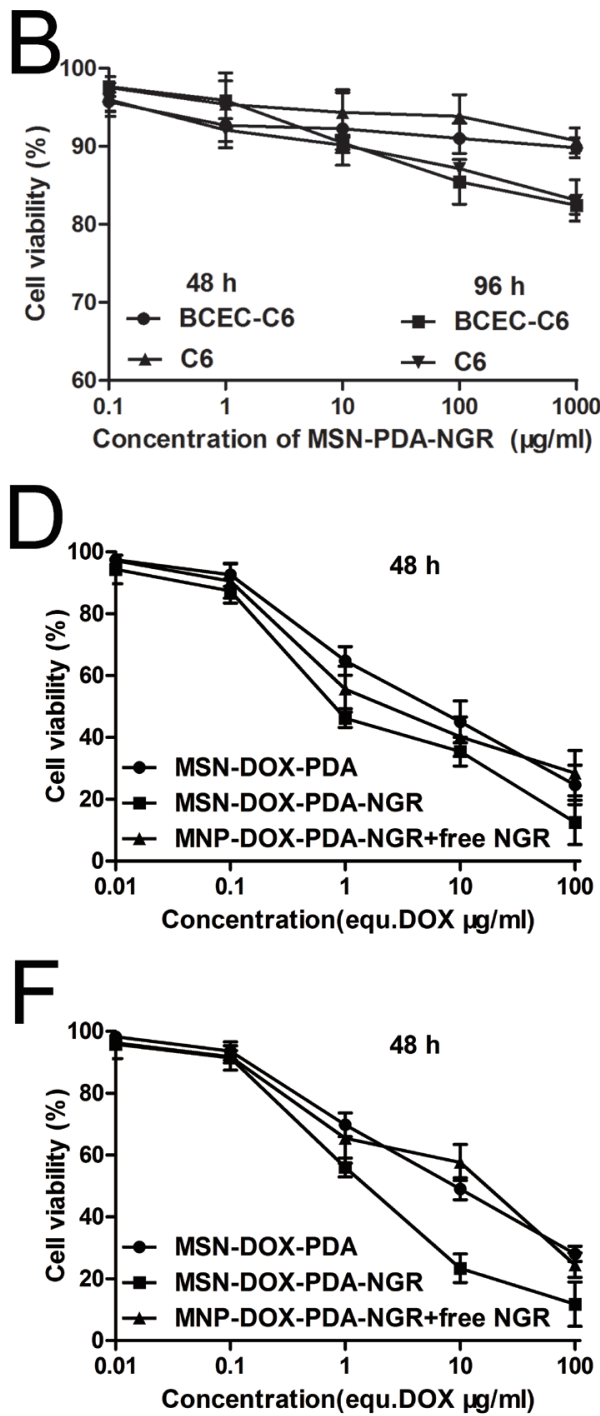

Figure 4: Cell viability following treatment with various NPs. A. Viability of C6 cells after treatment with free DOX. B. Viability of BCEC-C6 and C6 cells after treatment with blank NPs. Viability of BCEC-C6 cells after treatment with different DOX formulations for C. 24 and D. 48 h. Viability of C6 cells after treatment with different DOX formulations for E. 24 and F. 48 h. 


\section{Subcellular localization of dual-targeted NPs}

The results that the monensin (lysosome inhibitor) had an obvious inhibitory effect on the uptake of the NPs suggest that the uptake and release of NPs partly depended on the acidic environment in the lysosomes. To demonstrate this hypothesis directly, we examined the subcellular localization of the MSN-DOX-PDA-NGR in the $\mathrm{C} 6$ and $\mathrm{BCEC}-\mathrm{C} 6$ cells using confocal laser scanning microscopy. The lysosomes showed green fluorescence after the cells were stained with organelle-selective dyes while the NPs showed red fluorescence. The colocalization of the NPs with the organelle-selective dyes was indicated by the yellow color in the superimposed image. As shown in Figure 6, the MSN-DOX-PDA-NGR was localized in the lysosomes of the $\mathrm{C} 6$ and BCEC-C6 cells, suggesting that following its uptake by the cells, the NPs was subsequently delivered to lysosomes.

\section{In vitro transendothelial permeability and dual- targeting of NPs in BBB model}

The positive results of the experiments on the BCEC-C6 and C6 cells might not persuasively represent the dual-targeting capacity of MSN-DOX-PDA-NGR because of the extreme differences between the in vitro and in vivo conditions. Therefore, the in vitro BBB model was constructed to assess the transport efficiency of the different DOX formulations. Figure 7A shows that the in vitro transport ratios across the BBB increased with incubation time. After the 12-h incubation, the transport ratio was 13.16 and $24.59 \%$ for the MSN-DOX-PDA and MSN-DOX-PDANGR, respectively. In addition, the transport ratio for the MSN-DOX-PDA-NGR group was consistently the highest among these groups at different times, except $24 \mathrm{~h}$. These results suggest that the transportation of the NPs across in vitro BBB model was significantly enhanced by the NGR modification $(p<0.001)$. However, when the excess NGR was pre-incubated to saturate the $\mathrm{CD} 13$ binding site of the in vitro $\mathrm{BBB}$, the transport ratio of the MSN-DOX-PDA-NGR was significantly reduced. Therefore, it can be concluded that NGR might mediate the transport of MSN-DOX-PDANGR across the BBB via facilitative receptor-mediated transcytosis. The integrity of the BCEC monolayer was monitored by determining the trans-endothelial electrical resistance (TEER) during the entire experiment (data not shown), and no significant reduction was observed except the $24 \mathrm{~h}$ time point. This indicated that the drug transport did not compromise the BBB barrier properties, and the NPs transport across the BBB was via the transcellular but not the paracellular pathway within 12 hours. Surprisingly, at $24 \mathrm{~h}$, the transport ratios of all the groups reached approximately $50 \%$. These results may have been due to the breakdown of the BCEC monolayer as the TEER values were significantly reduced in all groups at the same time.

In addition, an in vitro coculture model was established to evaluate whether the drug-loaded NPs transported across the BBB could be taken up by the $\mathrm{C} 6$ cells below and induce cell death. Figure 7B and 7C show that the MSN-DOX-PDA-NGR group still exhibited the highest accumulation of DOX and cytotoxicity against the $\mathrm{C} 6$ cells. These results demonstrate that MSN-DOXPDA-NGR exhibited a "dual-targeting effect," which first targeted and transported across the BCEC monolayer and then targeted the C6 cells below.

\section{In vivo imaging of dual-targeted NPs}

To evaluate the in vivo BBB penetration and NGRtargeting efficacy of different DOX formulations, non-

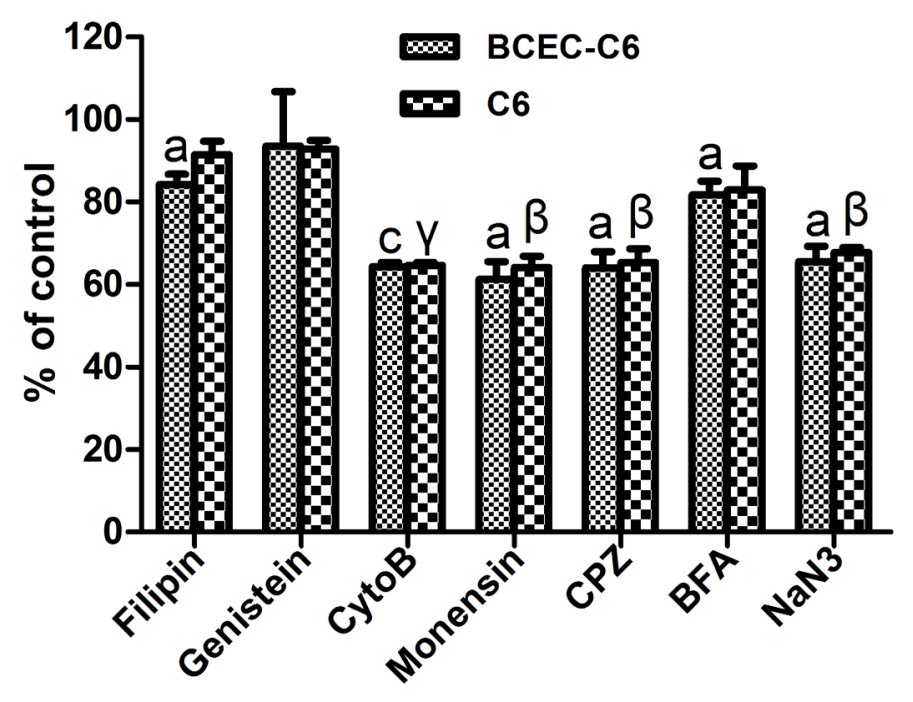

Figure 5: Effect of inhibitors on cellular uptake of MSN-DOX-PDA-NGR by BCEC-C6 and C6 cells. ${ }^{\mathrm{a}} p<0.05$ and ${ }^{\mathrm{c}} p<$ 0.001 compared with control BCEC-C6 cells; ${ }^{\beta} p<0.01$ and ${ }^{\gamma} p<0.001$ compared with control C6 cells $(\mathrm{n}=3)$. 

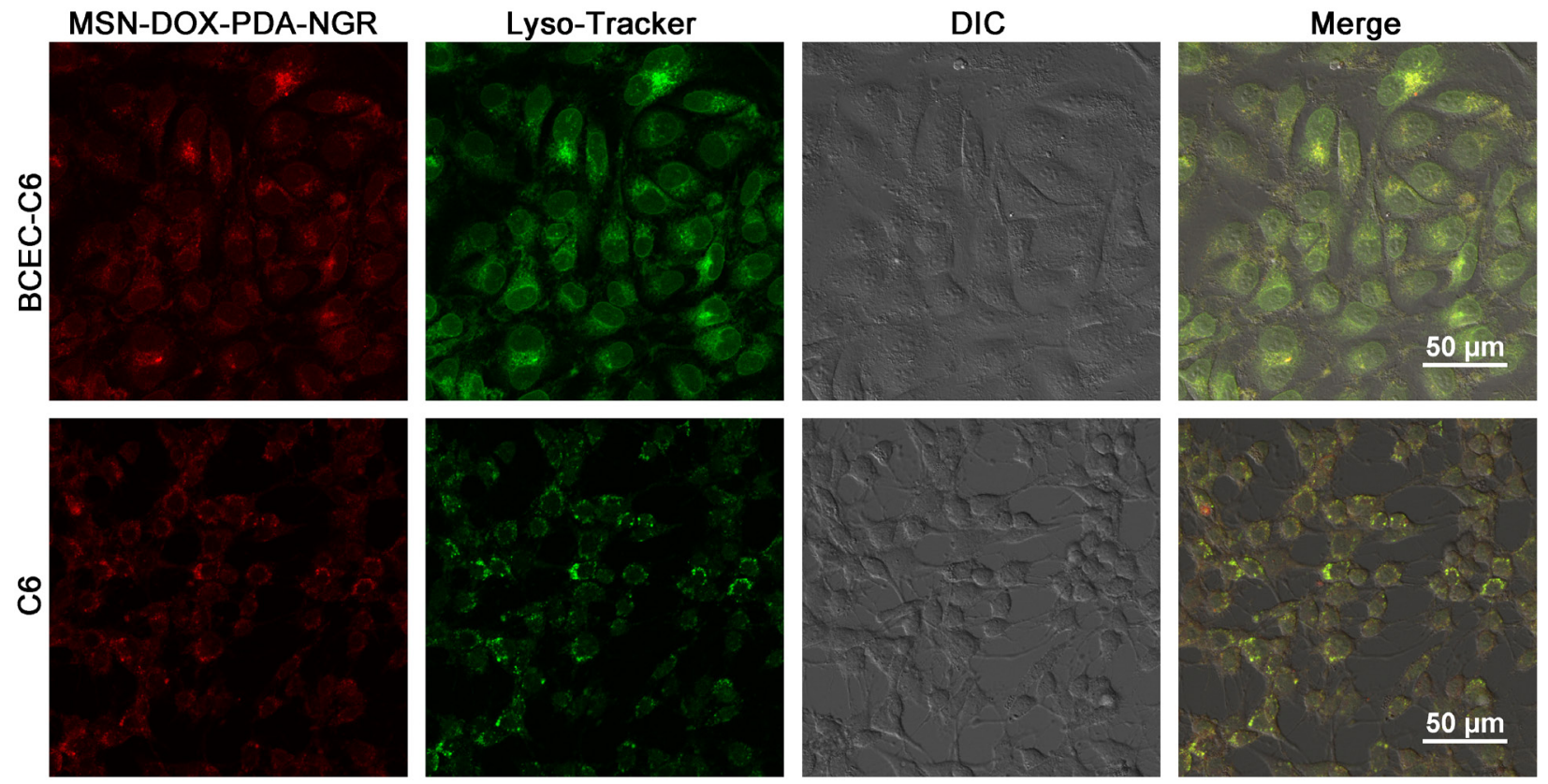

Figure 6: Confocal microscopy images of intracellular localization of MSN-DOX-PDA-NGR in A. BCEC-C6 and B. C6 cells. Lysosomes and nanoparticles (NPs) were distinguished using Lysotracker (green) and DOX (red), respectively.
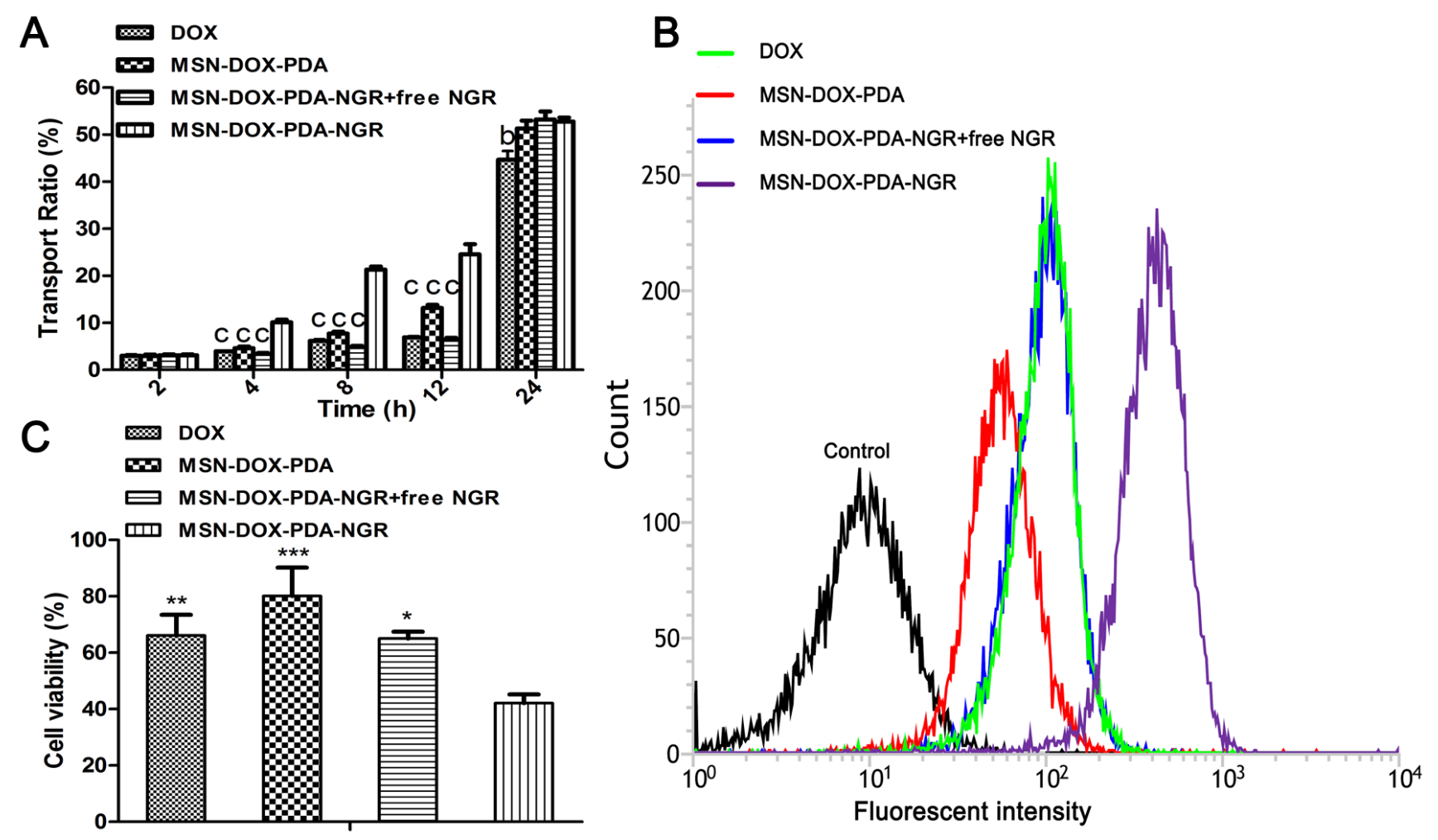

Figure 7: In vitro transport ratios (\%) of various NPs. A. Transport ratio across BCEC-C6 monolayer of different DOX formulations during 24 hours. B. Flow cytometric analysis and C. viability of C6 cells (below) after treatment with different DOX formulations; ${ }^{\mathrm{b}} p<$ $0.01,{ }^{c} p<0.001,{ }^{*} p<0.05,{ }^{* *} p<0.01$, and ${ }^{* * *} p<0.001$ compared with MSN-DOX-PDA-NGR $(\mathrm{n}=3)$. 
invasive fluorescence imaging was conducted to track the biodistribution of NPs in C6 cell orthotopic glioma nude mice. A significantly higher fluorescence intensity at the brain tumor site was observed in the MSN-DOX-PDANGR group than in the MSN-DOX-PDA and free DOX groups (Figure 8A), indicating that MSN-DOX-PDA-NGR accumulated more in the glioma-related region. Moreover, the ratios of the right/left brain hemisphere fluorescence intensity were 1.05, 1.23, and 2.03 for DOX, MSN-DOXPDA, and MSN-DOX-PDA-NGR, respectively (Figure $8 \mathrm{~B}$ and $8 \mathrm{C}$ ). In addition, the fluorescence intensity of the right brain in the MSN-DOX-PDA-NGR group was significantly higher than it was in the MSN-DOX-PDA and DOX groups. This observation indicates that MSNDOX-PDA-NGR had an excellent dual-targeting delivery capability for glioma tissues. Furthermore, the distribution of the different DOX formulations in the other investigated organs was comparable (Figure 8B and 8D).

\section{In vivo glioma distribution of dual-targeted NPs}

We sought to further determine whether MSN-DOXPDA-NGR specifically targeted the tumor cells in vivo. Therefore, we studied the glioma-targeting capacity of the MSN-DOX-PDA-NGR qualitatively using fluorescence microscopy in tumor bearing rats. As shown in Figure 9, only a few MSN-DOX-PDA NPs were distributed in the glioma region owing to the EPR effect. However, an obviously higher distribution of the NGR-modified NPs was observed at the glioma site and in the cancerous brain tissues surrounding the glioma than in the normal regions. These findings were consistent with the ex vivo fluorescence images of the NPs distribution in gliomabearing nude mice.

\section{In vivo drug release and liver deposition}

To evaluate the drug delivery capacity of the NPs in tumor bearing rats quantitatively, the tumor-bearing and contralateral brain tissues, as well as liver tissues, were harvested after treatment with the different DOX formulations, and the amount of DOX was measured using HPLC analysis (Figure 10). The DOX deposition in the right brain hemisphere of the MSN-DOX-PDANGR group was significantly greater than that of the MSN-DOX-PDA and DOX groups (2.55 and 2.43-fold, respectively). The amount of DOX in the right and left brain hemispheres showed no obvious difference between the DOX and MSN-DOX-PDA groups. However, the DOX deposition was significantly higher in the tumor-

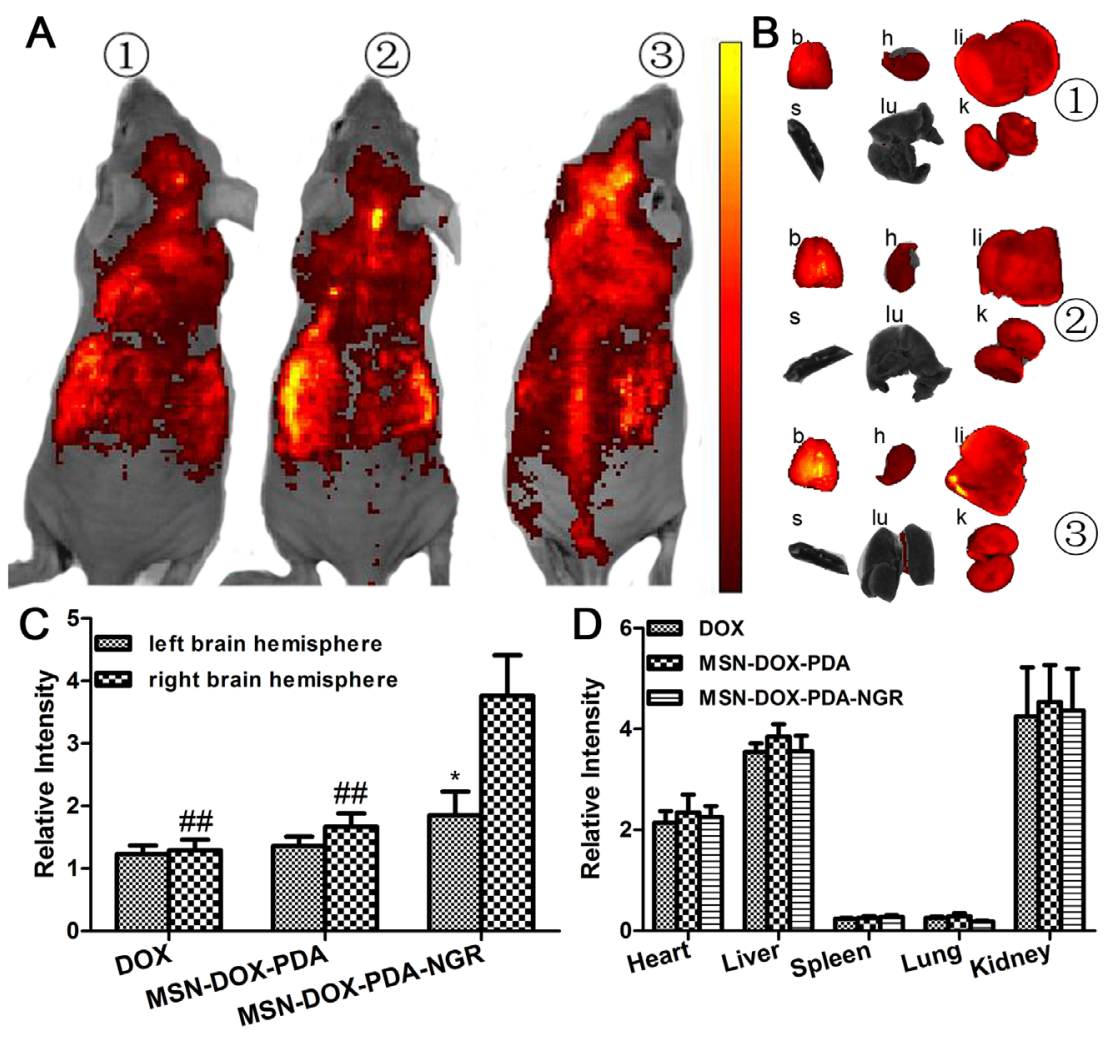

Figure 8: In vivo and Ex vivo fluorescent imaging of various NPs. A. In vivo fluorescent imaging of different DOX formulations $6 \mathrm{~h}$ post i.v. injection. B. Ex vivo fluorescent imaging of dissected organs. Semi-quantitative fluorescence intensity of C. left and right brain hemisphere and D. other major organs. Mouse 1, injection of free DOX; mouse 2, injection of MSN-DOX-PDA; mouse 3, injection of MSN-DOX-PDA-NGR. Key: b, brain; h, heart; li, liver; s, spleen; lu, lung; k, kidney; ${ }^{*} p<0.05$ compared with right brain hemisphere and ${ }^{\#} p<0.01$ compared with right brain hemisphere in MSN-DOX-PDA-NGR group $(\mathrm{n}=3)$. 
bearing brain tissue than it was in the contralateral normal brain tissue in the MSN-DOX-PDA-NGR group ( $p<$ $0.001)$. These results are in accordance with those of the ex vivo imaging and in vivo glioma distribution of the dual-targeted NPs. Moreover, the DOX deposition in liver tissues showed no significant difference among the three groups.

\section{In vivo antitumor and antiangiogenesis effects of dual-targeted NPs}

We assumed that the dual-targeted NPs have a more powerful antitumor activity since the MSN-DOX-PDANGR increased the DOX accumulation at the tumor site. To evaluate the antitumor effect of the MSN-DOX-PDANGR in vivo, we examined the apoptotic and necrotic regions in the brains of tumor bearing rats using $H \& E$ staining and TUNEL assay after treatment with different DOX formulations. As shown in Figure 11A and 11B, obvious apoptotic and necrotic tumor cells were observed in MSN-DOX-PDA-NGR group on day 10 compared with those in other groups. In addition, a more severe cell apoptotic and necrotic was detected on day 17, suggesting that NGR-decoration NPs could not only target but also put down the tumor cells in vivo.

To determine the antiangiogenic activity simultaneously, we assessed the microvessel density using immunohistochemistry. As shown in Figure 11C, the microvessels in the glioma-bearing rat brains were CD31-positive. There were obviously fewer microvessels in the MSN-DOX-PDA-NGR group than there were in other groups. The results were in accordance with the
H\&E staining and TUNEL assay, clearly indicating that MSN-DOX-PDA-NGR possesses dual-targeting capacity in vivo.

To further evaluate the therapeutic activity in vivo, the survival time of the tumor-bearing rats after treatment was investigated using the Kaplane-Meier survival curve. As shown in Figure 11D, the median survival times for the saline, DOX, MSN-DOX-PDA, and MSN-DOX-PDANGR groups were 19, 21, 21.5, and 32 days, respectively. Compared with the saline group, the DOX and MSNDOX-PDA did not show an improvement in the survival time. However, treatment with MSN-DOX-PDA-NGR significantly prolonged the median survival time compared with that for other groups.

MSN-DOX-PDA-NGR showed significant antitumor and antiangiogenesis effects and obviously prolonged the survival time compared with the other groups. These observations suggest that the MSNDOX-PDA-NGR with dual-targeting characteristics possessed the most effective therapeutic activity of all the formulations investigated.

\section{In vivo biological safety study}

The potential in vivo toxicity of NPs for drug delivery is always of great concern. For safety purpose, we evaluated the in vivo toxicity of the drug carrier in healthy adult male rats treated with MSN-PDA-NGR by tail vein injections at one $100 \mathrm{mg} / \mathrm{kg}$ dose administered every 3 days for 4 weeks. The increase in body mass of the MSN-PDA-NGR and saline groups showed a comparable tendency over the 4 weeks. Furthermore, we conducted
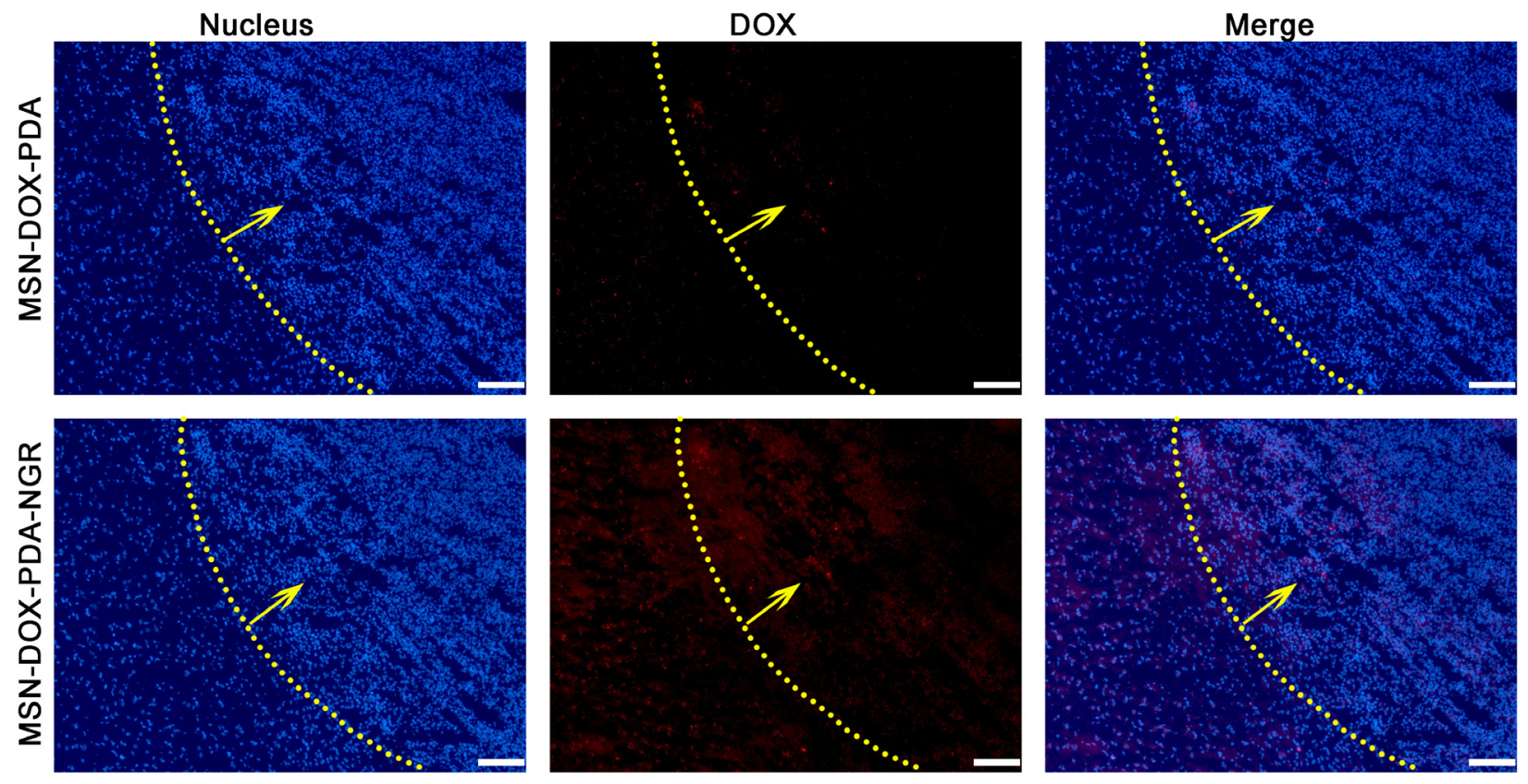

Figure 9: In vivo distribution of different DOX formulations in brains of glioma-bearing rats. Nuclei were stained with DAPI (blue) while DOX distribution is in red. Yellow line and arrow, border and direction of glioma, respectively; scale bar, $50 \mu \mathrm{m}$. 


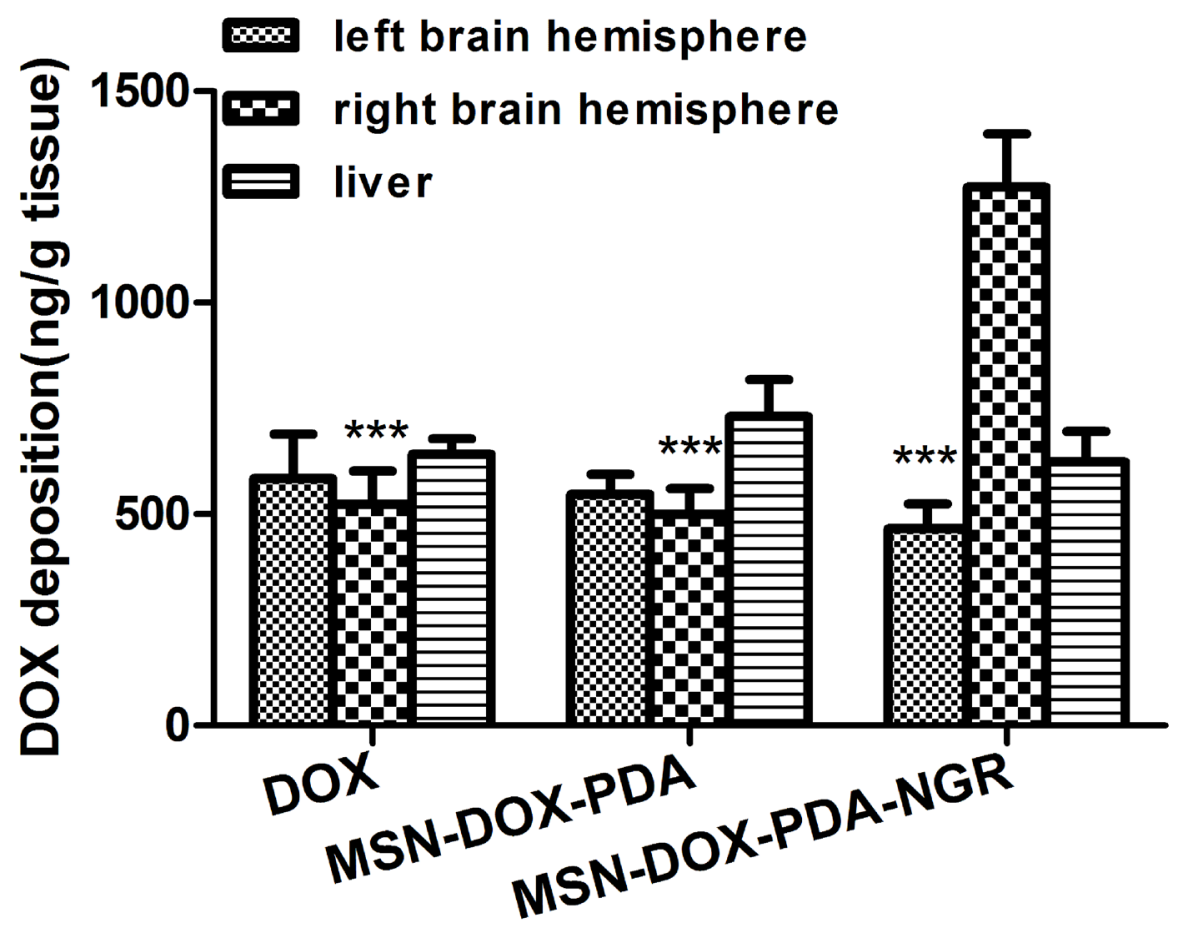

Figure 10: DOX deposition in tumor-bearing brain tissue, contralateral brain tissue, and liver tissue after treatment with different DOX formulations. ${ }^{* * *} p<0.001$ compared with the right brain hemisphere in MSN-DOX-PDA-NGR group (n $=3$ ).
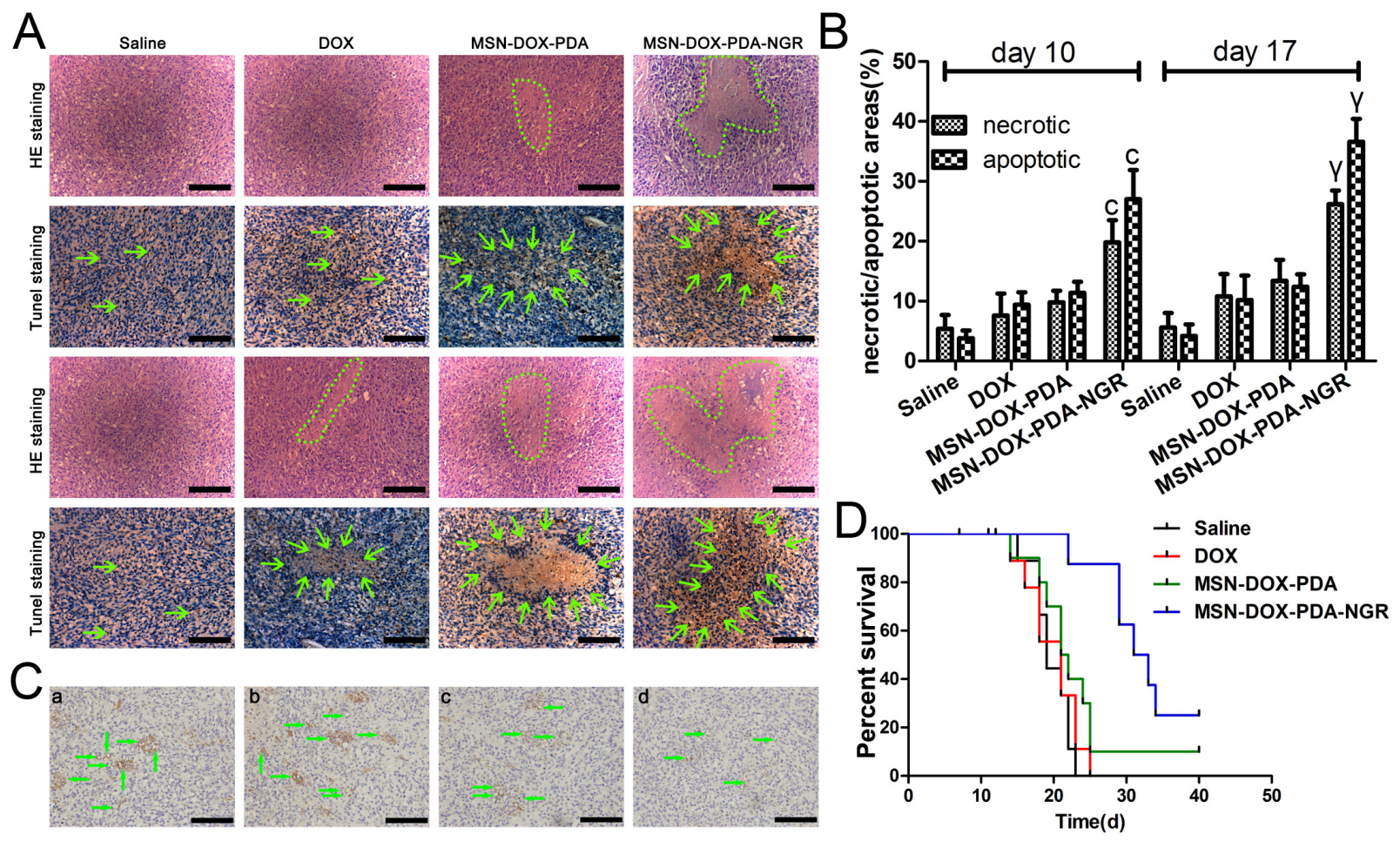

Figure 11: In vivo antitumor and antiangiogenesis effects of dual-targeted NPs. A. H\&E and TUNEL staining after 10 and 17 days (upper and lower two rows, respectively) post transplantation. B. The ratios of the necrotic/apoptotic areas within the tumor. C. CD31positive microvessels in glioma-bearing rat brains. D. Survival curve (Kaplan-Meier plot) of glioma-bearing rats treated with different DOX formulations. Green circle and arrows in A indicate necrotic regions and cell apoptosis body in tumor interior, respectively; a, control group; b, free DOX group; c, MSN-DOX-PDA group; d, MSN-DOX-PDA-NGR group. Green arrow in C, microvessel; scale bar, $50 \mu \mathrm{m}$. ${ }^{c} p<0.001$ compared with other groups at day $10 ;{ }^{\gamma} p<0.001$ compared with other groups at day $17(\mathrm{n}=5)$. 
the histological analyses, which revealed no obvious pathological lesions or impairment in the major tissues from rats that received MSN-PDA-NGR for 4 weeks (Figure 12).

\section{DISCUSSION}

Dual-targeting drug delivery systems that target some overexpressed receptors on both tumor neovasculature and cells have been developed. These systems offer a great strategy for overcoming the limitation of current antiangiogenesis therapy by combining vasculature damage and traditional anticancer therapy [29]. The main objective of this study was to verify the hypothesis that NGR-modified drug delivery systems could not only kill brain tumor angiogenic blood vessels, which indirectly starve the tumor cells supported by these vessels, but also penetrate the brain tumor interstitial space, thereby inducing direct tumor cell death. Briefly, NGR-conjugated NPs (MSN-DOX-PDA-NGR) could serve as a promising dual-targeting drug carrier for brain glioma and neovasculature chemotherapy.

Recent studies have shown that MSN employed as a targeting carrier possesses low cytotoxicity and good biocompatibility when applied to mammalian cells $[30,31]$. Dopamine is a well-known neurotransmitter. However, it has been demonstrated that its monomer does not exist in the PDA coating, which has been shown to be non-toxic in various cellular and in vivo studies [32, 33]. In our experiments, we also found that the in vitro cytotoxicity and in vivo toxicity of MSN-PDA-NGR were negligible. In summary, the evidence provided in these experiments suggests that our dual-targeting system is suitable for drug delivery.

For the in vitro experiments, the cellular uptake of the NPs and the subsequent cytotoxicity were enhanced by NGR modification, as demonstrated by the confocal images, flow cytometric analysis, and CCK-8 assay. To mimic in vivo conditions, the in vitro BBB model was constructed to assess the transport efficiency of the different DOX formulations. MSNDOX-PDA-NGR yielded the most efficient BBB transport ratio and subsequent cytotoxicity in the C6 cells before the integrated BBB destruction. The superior BBB permeability of the MSN-DOX-PDANGR may have contributed to the combination of the receptor-mediated cellular uptake and the caveolaeand clathrin-mediated endocytosis. After the BBB was perturbed by the chemotherapy drugs in the donor chamber, a vast amount of the DOX formulations passed through the disrupted barrier and accumulated in the "tumorous tissue fluid" in basal chamber. In agreement with the promising results of the in vitro model, the in vivo trans-endothelial superiority was demonstrated qualitatively by the ex vivo biodistribution and in vivo glioma distribution of the MSN-DOX-PDA-NGR, and quantitatively by the in vivo DOX deposition in the glioma-bearing rat brain.

Angiogenesis and vascular proliferation are regarded as critical factors for tumor growth, progression, and invasion and are established hallmarks of the malignancy degree of gliomas [34]. Numerous tumor cells depend on endothelial cells for their survival and invasion. Therefore, the method that compromised the tumor endothelial cells used in our experiment may amplify the therapeutic effect. The positive results of the in vivo immunohistochemical analysis of CD31 and histopathological changes in the glioma tissue verified the antiangiogenesis and antitumor effects of MSN-DOX-PDA-NGR, respectively. The prolonged median survival time of the MSN-DOXPDA-NGR-treated tumor-bearing rats further confirmed this amplified therapeutic effect. Overall, it is clear that the dual-targeting drug carrier did not only deliver the chemotherapy drugs into the tumor endothelial and glioma cells more efficiently, but it also induced more obvious cell apoptosis and necrosis. This observation indicates that the MSN-PDA-NGR NPs are a promising carrier for dual-targeted drug delivery. Since a higher CD13 level in the glioma (WHO grade III-IV) was detected than that in the gliom (I-II) using immunohistochemistry in our preliminary study (data not shown), we assumed that the MSN-DOX-PDA-NGR exhibited more powerful antitumor effects against the high-grade glioma than against low-grade. Therefore, we plan to establish different
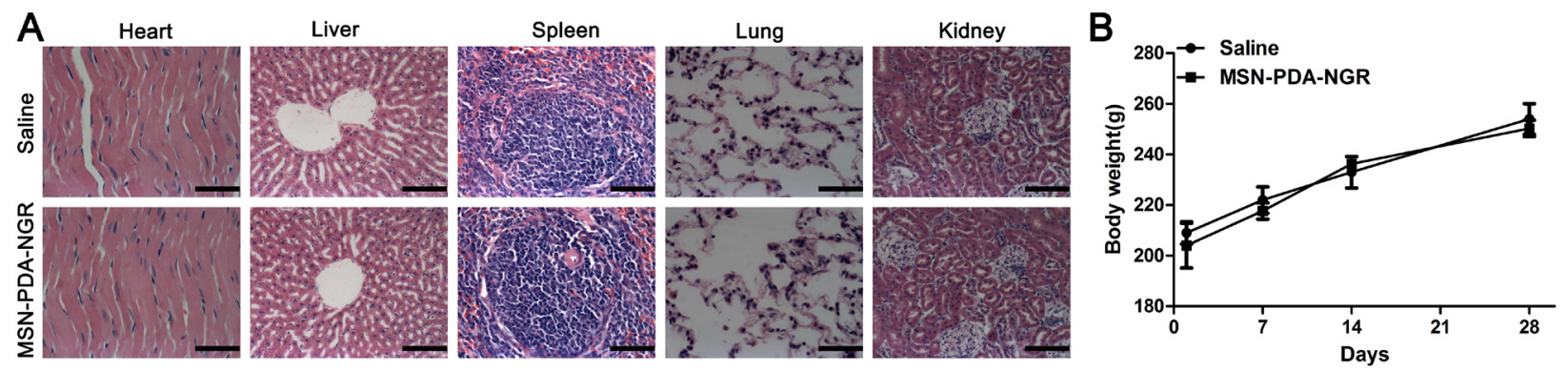

Figure 12: In vivo biological safety study. A. Hematoxylin and eosin (H\&E) staining of major organs harvested from rats treated with MSN-PDA-NGR for 4 weeks. B. Body mass of rats after treatment with MSN-PDA-NGR. 
grade human primary glioma animal model to evaluate the therapeutic effects of the NPs in the further study.

\section{MATERIALS AND METHODS}

\section{Materials and animals}

Mesoporous silica with a mean particle diameter of $150 \mathrm{~nm}$ was purchased from Nanjing XFNANO Materials Tech Co., Ltd., (Nanjing, China). The dopamine hydrochloride was purchased from Alfa Aesar (Ward Hill, MA, USA) while the NGR was synthesized by the Chinese Peptide Company (China). The DOX and all other chemicals were purchased from Sigma-Aldrich (St. Louis, MO, USA) unless otherwise specified. The plastic cell culture dishes and plates were purchased from Corning Inc., (Corning, NY, USA). The anti-CD31 and anti-CD13 antibodies were purchased from Abcam (MA, USA) while the anti-CD13 (fluorescein isothiocyanate, FITC) was purchased from Biorbyt (Cambridgeshire, UK). The primary BCEC cultures and astrocytes cells (AC) were prepared from 4-week- and 3-day-old Sprague-Dawley male rats, respectively, provided by the Experimental Animal Center of Chongqing Medical University. The C6, GL261, U251 cells were obtained from the Chinese Academy of Sciences Cell Bank (Shanghai, China). All animal experiments were performed according to the protocol evaluated and approved by the Ethics Committee of Chongqing Medical University.

\section{Preparation and characterization of dual- targeted NPs}

The MSN (12 mg) was added to $6 \mathrm{~mL}$ DOX solution $(1 \mathrm{mg} / \mathrm{mL})$ and the mixture was stirred in the dark for $24 \mathrm{~h}$ at $25^{\circ} \mathrm{C}$. Then, the DOX-loaded MSNs (MSN-DOX) were separated by centrifugation (12000 rpm, $10 \mathrm{~min}$ ), and washed with water to remove the residual DOX from the exterior surface of MSN. The filtrate and the wash solution were collected and combined as the remaining DOX solution. The loading amount of DOX was calculated as the difference between the initial and remaining DOX solution by using the fluorescence method using a calibration curve. Finally, the MSN-DOX were dried at $50^{\circ} \mathrm{C}$ under high vacuum overnight. The PDA coating was applied to modify the surface of the MSN as reported previously [15].

For the surface functionalization, the PDA-coated MSN-DOX (MSN-DOX-PDA) were resuspended in Tris buffer (10 mM, pH 8.5) containing NGR. The final concentrations of the NPs and ligands were 2 and 0.5 $\mathrm{mg} / \mathrm{mL}$, respectively. After $3-\mathrm{h}$ incubation at $25^{\circ} \mathrm{C}$ with rotation, the NPs were collected by centrifugation (12000 $\mathrm{rpm}, 10 \mathrm{~min}$ ), washed with water twice. The concentration of Asn-Gly-Arg (NGR) in the supernatant was determined using a high-performance liquid chromatography (HPLC) system (LCMS-2010, Shimadzu, Japan) equipped with a C18 column ( $4.6 \mathrm{~mm} \times 250 \mathrm{~mm}$, pore size $5-\mu \mathrm{m}$, Waters). Mobile phase, acetonitrile and water in a ratio of 70:30 $(\mathrm{v} / \mathrm{v}), \mathrm{pH} 3.08$; flow rate, $1.0 \mathrm{~mL} / \mathrm{min}$; sample injection volume, $10 \mu \mathrm{L}$; detection wavelength, $220 \mathrm{~nm}$. The encapsulation efficiency (EE) and loading content (LC) of drug, and the NGR conjugation efficiency (CE) were determined as follows: $\mathrm{EE}=\mathrm{DOX}$ encapsulated $/ \mathrm{DOX}_{\text {total }} \times 100$, $\mathrm{LC}=\mathrm{DOX}_{\text {encapsulated }} /$ /materials $\times 100, \mathrm{CE}=\mathrm{NGR}_{\text {conjugated }} /$ $\mathrm{NGR}_{\text {total }} \times 100$.

The particle size and zeta potential of NPs were determined using dynamic light scattering (DLS) with a Zeta Sizer 3000 HS (Malvern, USA). The morphology of the nanomaterial samples was observed using a transmission electron microscope (H-7600, Hitachi, Japan) at an acceleration voltage of $100 \mathrm{kV}$.

The drug release experiment was performed by diluting NP-DOX with PBS at $\mathrm{pH} 7.5$ and acetate buffer at $\mathrm{pH} 4.5$ at a concentration equivalent to $140 \mu \mathrm{g} /$ $\mathrm{mL}$ free DOX, and incubating at $37^{\circ} \mathrm{C}$ for $2,4,8,12$, 24,48 , and $72 \mathrm{~h}$. After incubation and centrifugation at $20000 \mathrm{rpm}$ to remove the NPs, the concentration of DOX was determined using HPLC analysis (mobile phase, acetonitrile:water, $70: 30(\mathrm{v} / \mathrm{v}), \mathrm{pH} 3.08$; flow rate, $1.0 \mathrm{~mL} /$ min; sample injection volume, $5 \mu \mathrm{L}$; detection wavelength, $233 \mathrm{~nm})$.

\section{CD13 expression in targeted cells}

The BCECs, C6, and AC cells were seeded at a density of $5 \times 10^{5}$ cells/dish. To promote the differentiation of the BCECs, coculture models were established with C6 or AC cells using Millicell hanging cell culture inserts (1- $\mu \mathrm{m}$ pore size, $24 \mathrm{~mm}$ diameter, $4.5 \mathrm{~cm}^{2}$ surface area, Millipore, USA). The BCECs were seeded in the six-well culture plates while the $\mathrm{C} 6$ or $\mathrm{AC}$ cells were in the donor chamber, and the cells were at a density of $1 \times 10^{5}$ cells/ well. When the cell confluency had attained $80 \%$ after 48 $\mathrm{h}$, the $\mathrm{C} 6$ cells, AC cells, BCECs, and BCEC-C6 cells, BCEC-AC cells were harvested, incubated with the antiCD13 antibody (FITC), mouse IgG2a K Isotype Control according to the manufacture's instruction. Then, the cells were analyzed using a fluorescence-activated cell sorting (FACS) Calibur flow cytometer (Becton Dickinson, Mountain View, CA, USA). The western blot analysis was further performed to quantify the CD13 levels in the single and cocultured cells according to a previously described method [35].

\section{Cellular uptake of dual-targeted NPs}

For the qualitative study, a laser scanning confocal microscope (Leica SP2, Heidelberg, Germany) was used to investigate the uptake of NPs into C6 cells. The cells were cultured overnight at a density of $4 \times 10^{4}$ cells/confocal dish and then treated with DOX-MSN-PDA, MSN-DOX- 
PDA-NGR, or MSN-DOX-PDA-NGR + free NGR at a DOX concentration of $0.5 \mu \mathrm{g} / \mathrm{mL}$ for $4 \mathrm{~h}$. Then, the cells were rinsed thrice with phosphate-buffered saline (PBS), fixed with $4 \%(\mathrm{v} / \mathrm{v})$ paraformaldehyde for $15 \mathrm{~min}$, stained with 4',6-diamidino-2-phenylindole (DAPI) for $5 \mathrm{~min}$, and finally washed thrice with PBS before observation.

For the quantitative study, flow cytometry was used to measure the fluorescence intensity of DOX at excitation and emission wavelengths of 488 and $585 \mathrm{~nm}$, respectively. In brief, the $\mathrm{C} 6$ cells were treated with the different DOX formulations used in the quantitative study for $2 \mathrm{~h}$ in the dark, rinsed with PBS, and then harvested for detection. The method used to assess the cellular uptake of the NPs in the BCEC-C6, GL261, and U251 cells was the same as described above.

\section{Cytotoxicity assay of dual-targeted NPs}

The C6 cells were seeded into 96-well culture plates at a density of $5 \times 10^{3}$ cells/well the night before treatment. Then, free DOX, blank MSN-PDA-NGR, MSN-DOX-PDA, MSN-DOX-PDA-NGR, or MSN-DOXPDA-NGR + free NGR with different concentrations were added to the wells of the 96-well plates and incubated together. At designated time points, $10 \mu \mathrm{L}$ of the CCK-8 solution was added to each well followed by incubation for $2 \mathrm{~h}$. The absorbance values $\left(\mathrm{A}_{450 \mathrm{~nm}}\right)$ were detected using a microplate reader (BioRad, 680, USA). The cell viability was calculated as follows: survival $(\%)=\left(\mathrm{A}_{450 \mathrm{~nm}}\right.$ of treated cells $/ A_{450 \mathrm{~nm}}$ of control cells $) \times 100$. The halfmaximal inhibitory concentration $\left(\mathrm{IC}_{50}\right)$ values were determined from the dose-effect curve and expressed as the concentration of DOX-equivalency. For the BCEC-C6 cells, the cytotoxicity of the different NPs was also determined in the BCEC-C6, GL261, and U251 cells using the same method described above.

\section{Cellular uptake mechanism of dual-targeted NPs}

The cellular uptake mechanism of dual-targeted NPs was performed as previously described [36]. The C6 cells were seeded at a density of $5 \times 10^{5}$ cells/well into six-well plates and incubated overnight. After a 30-min incubation with Dulbecco's modified Eagle's medium (DMEM), the cells were further incubated with the following inhibitors, sodium azide $\left(\mathrm{NaN}_{3}, 0.1 \%\right)$, filipin $(10 \mu \mathrm{g} /$ $\mathrm{mL})$, chlorpromazine hydrochloride (CPZ, $20 \mu \mathrm{g} / \mathrm{L})$, cytochalasin B (Cyto-B, $40 \mu \mathrm{M})$, monensin (100 nM), and brefeldin A (BFA, $20 \mu \mathrm{g} / \mathrm{mL}$ ) for another $30 \mathrm{~min}$. Then, the inhibitors were removed from the wells, and MSNDOX-PDA-NGR $(0.5 \mu \mathrm{g} / \mathrm{mL})$ and fresh samples of the inhibitors at the same concentrations used previously were added. After 1-h incubation, the cells were harvested by trypsinization and analyzed using flow cytometer. Cells that were incubated without any inhibitors served as the control. A similar method was also used to evaluate the uptake mechanism in the BCEC-C6 cells.

\section{Subcellular localization of dual-targeted NPs}

The subcellular localization of dual-targeted NPs was performed as previously described [36]. The C6 cells were cultured overnight in the confocal dish and treated with MSN-DOX-PDA-NGR $(0.5 \mu \mathrm{g} / \mathrm{mL})$ for $30 \mathrm{~min}$ at $37^{\circ} \mathrm{C}$ followed by incubation with $50 \mathrm{nM}$ LysoTracker Green (30 $\mathrm{min})$ and $10 \mathrm{mM}$ Hoechst 33342 (10 $\mathrm{min})$ to visualize the lysosome and nuclei using a laser scanning confocal microscope. A similar method was also used to evaluate the subcellular localization in the BCEC-C6 cells.

\section{Transport across BBB and dual-targeting effects of NPs in vitro}

The transport ratio (\%) was measured to assess the permeability of the drug carriers through the BBB. The BCECs were seeded into the Millicell hanging cell culture insert at a density of $1 \times 10^{5}$ cells/well and cocultured with the $\mathrm{C} 6$ cells for 7 days, supplemented with hydrocortisone $(500 \mathrm{nM})$ and cyclic adenosine monophosphate (cAMP, $312.5 \mu \mathrm{M})$ to induce barrier tightness [37-39]. Before starting the experiment, the tightness of the BCEC monolayer was monitored by measuring the transendothelial electrical resistance (TEER) using a TEER instrument (Millicell-RES, Millipore, USA). Only BCEC monolayers with TEER above $200 \Omega \mathrm{cm}^{2}$ were selected for the subsequent experiment [40]. Then, the BCEC monolayer described above was inserted into another six-well culture plate containing fresh medium, and different DOX formulations (free DOX, DOX-MSN-PDA, MSN-DOX-PDA-NGR, and MSN-DOX-PDA-NGR + free NGR) were added to the donor chamber at a DOX concentration of $100 \mu \mathrm{g} / \mathrm{mL}$, followed by incubation at $37^{\circ} \mathrm{C}$. A $300-\mu 1$ sample was withdrawn from the acceptor chamber at 2, 4, 8, 12, and $24 \mathrm{~h}$ and an equal volume of fresh DMEM was added immediately after each sampling. The concentration of DOX was determined using an HPLC analysis. The transport ratio was calculated using the following formula: ratio $(\%)=\left(\mathrm{W}_{\mathrm{n}} / \mathrm{W}\right) \times 100$; where, $\mathrm{W}_{\mathrm{n}}$ is the DOX amount in the samples taken from basal chamber at the nth $\mathrm{h}(\mathrm{n}=2,3,8,12$, and 24$)$, and $\mathrm{W}$ is the DOX amount in the control added to the apical chamber. To assess the dual-targeting effect of the carriers in vitro, the $\mathrm{BCEC}$ monolayer was inserted into the six-well culture plate where the $\mathrm{C} 6$ cells had been cultured overnight at a density of $1 \times 10^{5}$ cells/well and they were incubated together for $24 \mathrm{~h}$ to establish the coculture model in vitro [41]. Then, different DOX formulations were added to the apical chamber at a final DOX concentration of 100 $\mu \mathrm{g} / \mathrm{mL}$. For the cellular uptake, the C6 cells in the lower chamber were harvested for flow cytometric analysis after $8 \mathrm{~h}$ co-incubation. For the cell survival evaluation, the $\mathrm{C} 6$ cells were further cultured alone for $48 \mathrm{~h}$ and then measured using a CCK- 8 assay. At the end of the experiment, the TEER was measured again to check the integrity of the BCEC monolayers. 


\section{In vivo imaging of dual-targeted NPs in glioma- bearing nude mice}

The C6 cell orthotopic glioma nude mouse model was established by injecting C6 cells $\left(1 \times 10^{6}\right.$ cells in $10 \mu \mathrm{L}$ PBS, $0.01 \mathrm{M}, \mathrm{pH}$ 7.4) into the right brain of male nude mice $(2 \mathrm{~mm}$ lateral to the bregma and $5.0 \mathrm{~mm}$ deep from the dura) at a rate of $1.0 \mu \mathrm{L} / \mathrm{min}$ using a stereotaxic apparatus. The growth of the tumor was monitored longitudinally using magnetic resonance imaging (MRI). On day 10 after the implantation, the different DOX formulations were injected via the tail vein at a dose of 100 $\mathrm{mg} / \mathrm{kg}$ body weight. Then, $6 \mathrm{~h}$ post-injection, the in vivo distribution of the associated fluorescence was visualized using the IVIS animal imaging system (PerkinElmer, USA). Then, 24 h post-injection, the ex vivo images of the major organs were also captured after they were harvested and rinsed with PBS thrice.

\section{In vivo glioma distribution of dual-targeted NPs}

The glioma-bearing rat model was established using the method described above. Then, $8 \mathrm{~h}$ after treatment with DOX-MSN-PDA and MSN-DOX-PDA-NGR, the rats were anesthetized by the intraperitoneal (ip) administration of $5 \%$ chloral hydrate, followed by heart perfusion with saline and $4 \%$ paraformaldehyde. Subsequently, the brains were removed, fixed in $4 \%$ paraformaldehyde for $24 \mathrm{~h}$, and sequentially cryoprotected with 15 and 30\% sucrose solutions until subsidence was observed with each exposure. Then, the brains were frozen in optimal cutting temperature (OCT) gel (Sakura, Torrance, CA, USA) at $-30^{\circ} \mathrm{C}$ and cut into $20-\mu \mathrm{m}$ sections, which were counterstained with $1 \mathrm{mg} / \mathrm{mL}$ DAPI for $5 \mathrm{~min}$ at $25^{\circ} \mathrm{C}$. Then, the slides were observed using a fluorescence microscope (Leica, Germany).

\section{In vivo quantification of drug release}

The glioma-bearing rats were divided into three groups and injected with free DOX, MSN-DOX-PDA, and MSN-DOX-PDA-NGR at a DOX dose of $5 \mathrm{mg} / \mathrm{kg}$ per animal. Then, $2 \mathrm{~h}$ post-treatment, the brain tissues were harvested after anesthetization and perfusion, and then divided into left (control) and right (tumor tissue containing) brain hemispheres. These brain samples were then homogenized and soaked in acidified ethanol $(50 \%$ ethanol in $0.3 \mathrm{~N}$ hydrochloric acid, $\mathrm{HCl}$ ) for $24 \mathrm{~h}$ at $4{ }^{\circ} \mathrm{C}$ to extract the DOX completely [42]. After drug extraction, the samples were centrifuged at $14000 \mathrm{rpm}$ for $10 \mathrm{~min}$ using a freezing centrifuge (Sigma 3-30K, Heraeus Co., Germany). The concentration of DOX in the clear supernatant was analyzed using an HPLC method and expressed per gram of tissue. The DOX deposition in the liver tissues was also quantified to compare the temporary toxicity among those groups, using the same procedures above.

\section{In vivo antitumor and antiangiogenesis effects of dual-targeted NPs}

The glioma-bearing rats were randomly divided into four groups of 16 each and injected with $100 \mu \mathrm{L}$ of free DOX, DOX-MSN-PDA, MSN-DOX-PDA-NGR (DOX dose, $5 \mathrm{mg} / \mathrm{kg}$ ), or saline via the tail vein on day $5,8,11$, and 14 after the C6 cells implantation. On day 5 and 12 post-treatment, three rats from each group were euthanized. The brains were harvested, fixed with $10 \%$ neutral formalin at $4^{\circ} \mathrm{C}$ for $48 \mathrm{~h}$, embedded in paraffin, and cut into 5- $\mu \mathrm{m}$ sections, which were stained with hematoxylin and eosin (H\&E) using routine protocols and Tdt-mediated d-uridine triphosphate (UTP) nickend labeling (TUNEL) using a kit, following the recommended protocol, to identify the histopathological changes. Simultaneously, CD31-specific staining was applied to assess the microvessel density (MVD) of the tumor tissues immunohistochemically. Ten tumorbearing rats from each group were survival-monitored, and the survival data were analyzed using the log-rank test.

\section{In vivo biological safety study}

Healthy adult male Sprague-Dawley rats were treated with MSN-PDA-NGR by tail vein injection (100 $\mu \mathrm{L}, 100 \mathrm{mg} / \mathrm{kg}$ ) one dose every 3 days for 4 weeks. Rats treated with saline were used as controls. The body mass was recorded at day $1,7,14,21$, and 28 post-treatment. The main organs including the brain, heart, lungs, liver, spleen, and kidneys were harvested after the final treatment followed by H\&E staining to examine the toxicity in vivo.

\section{Statistical analysis}

All the experiments were performed in triplicate. The acquired data are presented as mean \pm standard deviation (SD). The statistical significance was determined using ANOVA and $t$-test. $p<0.05$ was considered significant.

\section{CONCLUSION}

In this study, the MSN-PDA-NGR NPs were successfully established for the effective dualtargeting of BCEC-C6 and $\mathrm{C} 6$ cells. The drug carrier enhanced the cellular uptake of the NPs and the subsequent cytotoxicity significantly, as well as the BBB transportation ability in vitro. Furthermore, the dual-targeting drug delivery system exhibited a superior antiangiogenesis and antiglioma efficacy and negligible toxicity in vivo. In summary, these promising results indicate that the MSN-DOX-PDA-NGR could have great potential for the treatment of glioma. 


\section{ACKNOWLEDGMENTS}

The authors thank Bin Tan for his technical assistance with flowcytometry. We also thank Qiang Xi for his assistance with the HPLC method and analysis. This work was supported by Grants from the National Natural Science Foundation of China (Nos. 81201066, 81371674, 81471676, and 81401505) and the Chongqing Natural Science Foundation Project (Nos. CSTC2013jcyjA10054 and CSTC2014jcyjA10050).

\section{CONFLICTS OF INTEREST}

The authors declare that no competing financial interests exist.

\section{REFERENCES}

1. Alam MI, Beg S, Samad A, Baboota S, Kohli K, Ali J, Ahuja A, Akbar M. Strategy for effective brain drug delivery. European Journal of Pharmaceutical Sciences. 2010; 40:385-403.

2. Ricard D, Idbaih A, Ducray F, Lahutte M, Hoang-Xuan K, Delattre JY. Primary brain tumours in adults: The Lancet. Lancet. 2012; 379:1984-1996.

3. Pang Z, Feng L, Hua R, Chen J, Gao H, Pan S, Jiang $\mathrm{X}$, Zhang $\mathrm{P}$. Lactoferrin-conjugated biodegradable polymersome holding doxorubicin and tetrandrine for chemotherapy of glioma rats. Molecular pharmaceutics. 2010; 7:1995-2005.

4. Xinyi J, Qiuyue R, Jijin G, Lingjun Z, Fengyi D, Chunlai F, Yike X, Xianyi S, Xiaoling F. Nanoparticles of 2-deoxyD-glucose functionalized poly(ethylene glycol)-copoly(trimethylene carbonate) for dual-targeted drug delivery in glioma treatment. Biomaterials. 2014; 35:518-529.

5. Kim SS, Rait A, Kim E, DeMarco J, Pirollo KF, Chang EH. Encapsulation of temozolomide in a tumor-targeting nanocomplex enhances anti-cancer efficacy and reduces toxicity in a mouse model of glioblastoma. Cancer letters. 2015; 369:250-258.

6. Kaluzova M, Bouras A, Machaidze R, Hadjipanayis CG. Targeted therapy of glioblastoma stem-like cells and tumor non-stem cells using cetuximab-conjugated ironoxide nanoparticles. Oncotarget. 2015; 6:8788-8806. doi: 10.18632/oncotarget.3554

7. Shim JS, Jin HK, Cho HY, Yum YN, Kim SH, Park HJ, Shim BS, Choi SH, Kwon HJ. Irreversible inhibition of CD13/aminopeptidase $\mathrm{N}$ by the antiangiogenic agent curcumin. Chemistry \& Biology. 2003; 10:695-704.

8. Wang RE, Niu Y, Wu H, Hu Y, Cai J. Development of NGR-based anti-cancer agents for targeted therapeutics and imaging. Anti-cancer agents in medicinal chemistry. 2012; 12:76-86.
9. Wang, Xun, Wang, Yiguang, Chen, Xiaomei, Wang, Jiancheng, Zhang, Xuan. NGR-modified micelles enhance their interaction with CD13-overexpressing tumor and endothelial cells. Journal of Controlled Release. 2009; 139:56-62.

10. Michael D, Jinzi Z, Joshua R, Jaffray DA, Christine A. APN/CD13-targeting as a strategy to alter the tumor accumulation of liposomes. Journal of Controlled Release. 2011; 154:298-305.

11. Yu C, Hangrong C, Deping Z, Yunbo T, Feng C, Jingwei F, Jianlin S. Core/Shell Structured Hollow Mesoporous Nanocapsules: A Potential Platform for Simultaneous Cell Imaging and Anticancer Drug Delivery. ACS nano. 2010; 4:6001-6013.

12. Tang F, Li L, Chen D. Mesoporous silica nanoparticles: synthesis, biocompatibility and drug delivery. Advanced materials. 2012; 24:1504-1534.

13. Li L, Tang F, Liu H, Liu T, Hao N, Chen D, Teng X, He J. In vivo delivery of silica nanorattle encapsulated docetaxel for liver cancer therapy with low toxicity and high efficacy. ACS nano. 2010; 4:6874-6882.

14. Liu T, Li L, Teng X, Huang X, Liu H, Chen D, Ren J, He J, Tang F. Single and repeated dose toxicity of mesoporous hollow silica nanoparticles in intravenously exposed mice. Biomaterials. 2011; 32:1657-1668.

15. Qishan Z, Tianran L, Hanyin W, Liangqia G, Peirong Y, Yanli H, Qingquan G, Jinzhi J, Fengfu F, Guonan C. Mussel-inspired polydopamine coated mesoporous silica nanoparticles as $\mathrm{pH}$-sensitive nanocarriers for controlled release. International journal of pharmaceutics. 2014; 463:22-26.

16. Jae Hong K, Minah L, Beum PC. Polydopamine as a biomimetic electron gate for artificial photosynthesis. Angewandte Chemie. 2014; 126:6482-6486.

17. Park J, Brust TF, Hong JL, Sang CL, Watts VJ, Yeo Y. Polydopamine-Based Simple and Versatile Surface Modification of Polymeric Nano Drug Carriers. ACS nano. 2014; 8:3347-3356.

18. Haeshin L, Dellatore SM, Miller WM, Messersmith PB. Mussel-inspired surface chemistry for multifunctional coatings. Science. 2007; 318:426-.

19. Qinze L, Bo Y, Weichun Y, Feng Z. Highly selective uptake and release of charged molecules by $\mathrm{pH}$-responsive polydopamine microcapsules. Macromolecular Bioscience. $2011 ; 11: 1227-1234$.

20. Cheng FF, Zhang JJ, Xu F, Hu LH, Abdel-Halim ES, Zhu JJ. $\mathrm{pH}-$ Sensitive Polydopamine Nanocapsules for Cell Imaging and Drug Delivery Based on Folate Receptor Targeting. Journal of Biomedical Nanotechnology. 2013; 9:1155-1163.

21. Petros RA, Desimone JM. Strategies in the design of nanoparticles for therapeutic applications. Dressnature Reviews Drug Discovery. 2010; 9:615-627. 
22. Fernandez CA, Baumhover NJ, Duskey JT, Khargharia S, Kizzire K, M D E, Rice KG. Metabolically stabilized long-circulating PEGylated polyacridine peptide polyplexes mediate hydrodynamically stimulated gene expression in liver. Gene Therapy. 2011; 18:23-37.

23. Yamamoto Y, Nagasaki Y, Kato Y, Sugiyama Y, Kataoka K. Long-circulating poly(ethylene glycol)-poly(D,L-lactide) block copolymer micelles with modulated surface charge. Journal of Controlled Release. 2001; 77:27-38.

24. Mellman I, Fuchs R, Helenius A. Acidification of the endocytic and exocytic pathways. Annual Review of Biochemistry. 1986; 55:663-700.

25. Tannock IF, Rotin D. Acid pH in tumors and its potential for therapeutic exploitation. Cancer Research. 1989; 49:4373-4384.

26. Pasqualini R, Koivunen E, R, Lahdenranta J, Sakamoto M, Stryhn A, Ashmun R, Shapiro L, Arap W, Ruoslahti E. Aminopeptidase $\mathrm{N}$ is a receptor for tumor-homing peptides and a target for inhibiting angiogenesis. Cancer Research. 2000; 60:722.

27. Plate KH, Breier G, Millauer B, Ullrich A, Risau W. Up-regulation of vascular endothelial growth factor and its cognate receptors in a rat glioma model of tumor angiogenesis. Cancer Research. 1993; 53:5822-5827.

28. Bhagwat SV, Lahdenranta J, Giordano R, Arap W, Pasqualini R, Shapiro LH. CD13/APN is activated by angiogenic signals and is essential for capillary tube formation. Blood. 2001; 97:652-659.

29. Fabio P, Chiara B, Danilo M, Michele C, Claudio G, Domenico R, Renato L, Allen TM, Angelo C, Mirco P. Vascular damage and anti-angiogenic effects of tumor vessel-targeted liposomal chemotherapy. Cancer Research. 2003; 63:7400-7409.

30. Di P, Anthony J, Sharma, Krishna K, Shi, Yan-Li, Bonnie B, Ouellette, Wayne. Cytotoxicity of mesoporous silica nanomaterials. Journal of Inorganic Biochemistry. 2008; 102:1416-1423.

31. Lu J, Liong M, Li Z, Zink JI, Tamanoi F. Biocompatibility, Biodistribution, and Drug-Delivery Efficiency of Mesoporous Silica Nanoparticles for Cancer Therapy in Animals. Small. 2010; 6:1794-1805.

32. Seonki H, Keum Yeon K, Hwang Jin W, Sung Young P, Dae LK, Yun LD, Haeshin L. Attenuation of the in vivo toxicity of biomaterials by polydopamine surface modification. Nanomedicine. 2011; 6:793-801.
33. Sook Hee K, Beum PC. Human endothelial cell growth on mussel-inspired nanofiber scaffold for vascular tissue engineering. Biomaterials. 2010; 31:9431-9437.

34. Puduvalli VK, Sawaya R. Antiangiogenesis - Therapeutic Strategies and Clinical Implications for Brain Tumors. Journal of Neuro-Oncology. 2000; 50:189-200.

35. Huang N, Chen S, Deng J, Huang Q, Liao P, Wang F, Cheng Y. Overexpression of S100A9 in human glioma and in-vitro inhibition by aspirin. European Journal of Cancer Prevention. 2013; 22:585-595.

36. Jiang X, Xin H, Ren Q, Gu J, Zhu L, Du F, Feng C, Xie Y, Sha X, Fang X. Nanoparticles of 2-deoxy-D-glucose functionalized poly(ethylene glycol)-co-poly(trimethylene carbonate) for dual-targeted drug delivery in glioma treatment. Biomaterials. 2014; 35:518-529.

37. Calabria AR, Weidenfeller C, Jones AR, Vries HED, Shusta EV. Puromycin-purified rat brain microvascular endothelial cell cultures exhibit improved barrier properties in response to glucocorticoid induction. Journal of Neurochemistry. 2006; 97:922-933.

38. Takata F, Dohgu S, Yamauchi A, Matsumoto J, Machida T, Fujishita K, Shibata K, Shinozaki Y, Sato K, Kataoka Y. In vitro blood-brain barrier models using brain capillary endothelial cells isolated from neonatal and adult rats retain age-related barrier properties. Plos One. 2013; 8: e55166.

39. Shayan G, Yong SC, Shusta EV, Shuler ML, Lee $\mathrm{KH}$. Murine in vitro model of the blood-brain barrier for evaluating drug transport. European Journal of Pharmaceutical Sciences. 2010; 42:148-155.

40. Ke W, Shao K, Huang R, Han L, Liu Y, Li J. Gene delivery targeted to the brain using an Angiopep-conjugated polyethyleneglycol-modified polyamidoamine dendrimer. Biomaterials. 2009; 30:6976-6985.

41. Gao H, Qian J, Cao S, Yang Z, Pang Z, Pan S. Precise glioma targeting of and penetration by aptamer and peptide dual-functioned nanoparticles. Biomaterials. 2012; 33:5115-5123.

42. Park J, Zhang Y, Vykhodtseva N, Jolesz FA, Nnold NJ. The kinetics of blood brain barrier permeability and targeted doxorubicin delivery into brain induced by focused ultrasound. Journal of Controlled Release. 2012; 162:134-142. 